\title{
Dynamic development of starch granules and the regulation of starch biosynthesis in Brachypodium distachyon: comparison with common wheat and Aegilops peregrina
}

Guanxing Chen ${ }^{\dagger}$, Jiantang Zhu ${ }^{\dagger}$, Jianwen Zhou', Saminathan Subburaj, Ming Zhang, Caixia Han, Pengchao Hao, Xiaohui Li and Yueming Yan*

\begin{abstract}
Background: Thorough understanding of seed starch biosynthesis and accumulation mechanisms is of great importance for agriculture and crop improvement strategies. We conducted the first comprehensive study of the dynamic development of starch granules and the regulation of starch biosynthesis in Brachypodium distachyon and compared the findings with those reported for common wheat (Chinese Spring, CS) and Aegilops peregrina.

Results: Only B-granules were identified in Brachypodium Bd21, and the shape variation and development of starch granules were similar in the B-granules of CS and Bd21. Phylogenetic analysis showed that most of the Bd21 starch synthesis-related genes were more similar to those in wheat than in rice. Early expression of key genes in Bd21 starch biosynthesis mediate starch synthesis in the pericarp; intermediate-stage expression increases the number and size of starch granules. In contrast, these enzymes in CS and Ae. peregrina were mostly expressed at intermediate stages, driving production of new B-granules and increasing the granule size, respectively. Immunogold labeling showed that granule-bound starch synthase (GBSSl; related to amylose synthesis) was mainly present in starch granules: at lower levels in the B-granules of Bd21 than in CS. Furthermore, GBSSI was phosphorylated at threonine 183 and tyrosine 185 in the starch synthase catalytic domain in CS and Ae. peregrina, but neither site was phosphorylated in Bd21, suggesting GBSSI phosphorylation could improve amylose biosynthesis.

Conclusions: Bd21 contains only B-granules, and the expression of key genes in the three studied genera is consistent with the dynamic development of starch granules. GBSSI is present in greater amounts in the B-granules of CS than in Bd21; two phosphorylation sites (Thr183 and Tyr185) were found in Triticum and Aegilops; these sites were not phosphorylated in Bd21. GBSSI phosphorylation may reflect its importance in amylose synthesis.
\end{abstract}

Keywords: Brachypodium Bd21, B-granules, Starch biosynthesis, Expression profiling, GBSSI, Phosphorylation

\section{Background}

Starch is the major storage carbohydrate in the seeds of cereal crops. Starch comprises approximately $90 \%$ and $65-75 \%$ of the dry weight of rice and wheat, respectively [1]. Starch consists of the glucose polymers amylose and amylopectin. Amylose is a relatively linear molecule consisting of (1-4)-linked units of D-glucopyranosyl, whereas amylopectin mainly consists of long chains of (1-4)-linked

\footnotetext{
* Correspondence: lixiaohui@cnu.edu.cn; yanym@cnu.edu.cn

${ }^{\dagger}$ Equal contributors

College of Life Science, Capital Normal University, 100048 Beijing, China
}

D-glucopyranosyl units with occasional branching (1-6) linkages that yield tandem linked clusters $(\sim 9-10 \mathrm{~nm}$ long each) [2]. In the current model of the multiple-cluster structure of amylopectin, A-chains are linked to other chains at their reducing ends, whereas B-chains carry 1 or more chains belonging to a cluster. B1-chains are present within single clusters, whereas B2- and B3-chains are long chains interconnecting many clusters. The only chain that contains a reducing terminal in an amylopectin molecule is called a C-chain [3]. Amylopectins from different species exhibit different chain length distributions with 
periodic occurrence of varying degrees of polymerization (DP). These chains are grouped into four fractions with DP in intervals 6-12 (A-chain), 13-24 (B1-chain), 25-36 (B2-chain), and $>37$ (B3- or more advanced chains) [4].

The endosperm of mature wheat (Triticum aestivum L.) contains three types of starch granules: A, B, and C. A-granules, from 10 to $50 \mu \mathrm{m}$ in diameter, constitute up to $70 \%$ of the volume and $10 \%$ of the total number of starch granules $[5,6]$. In contrast, B-granules, 5-9 $\mu \mathrm{m}$ in diameter, constitute approximately $30 \%$ of the volume and $90 \%$ of the total number of granules. Recent evidence indicates the presence of $\mathrm{C}$-granules with a diameter less than $5 \mu \mathrm{m}$; their small size makes them difficult to isolate and quantify, which commonly leads to them being classified with B-granules $[7,8]$. In wheat, B-granules negatively affect flour processing and bread quality [9], but positively affect pasta production [10]. This is thought to be due, at least in part, to the swelling capacity of B-granules: they bind more water than A-granules do [11]. The A- and B-granules in the Triticeae endosperm are separated in time and space. A-granules are formed approximately 4-14 days post-anthesis (DPA) when the endosperm is still actively dividing $[12,13]$. B-granules appear approximately 10-16 DPA, whereas the small C-granules first appear 21 DPA $[6,7]$. The genetic basis of the multimodal size distribution of starch in wheat and barley is of great interest because the physiochemical properties of each type of granule vary and contribute to the food and industrial end uses of Triticeae starch [14-16].

Amylose synthesis is controlled by granule-bound starch synthase (GBSSI) [17]. Amylopectins are synthesized by concerted reactions catalyzed by four enzyme classes: ADPglucose pyrophosphorylase (AGPase), starch synthase (SS), starch-branching enzyme (SBE), and starch-debranching enzyme (DBE). AGPase catalyzes the first reaction in starch synthesis, producing the activated glucosyl donor ADPglucose. Starch synthases catalyze transfer of glucose units from ADP-glucose onto the non-reducing end of a glucan chain to synthesize water-insoluble glucan polymers [18]. In cereal species, starch synthases are subdivided into granule-bound starch synthase (GBSS) and SS, responsible for amylopectin synthesis. GBSS is the only SS found exclusively within the starch granule and responsible for amylose synthesis [17]. The SS group consists of four isoforms designated SS-I, SS-II, SS-III, and SS-IV, which are localized predominantly at the granule surface [19]. Genetic analyses of Arabidopsis and rice suggest SS-I is required for the elongation of short A-chains within amylopectin $[20,21]$. The function of SS-II is the elongation amylopectin chains of DP 6-10 to produce intermediate-length chains of DP 12-25 [22]. Analysis of SS-III mutants suggests this enzyme class catalyzes the synthesis of long amylopectin chains, DP 25-35, or greater [23-25]. Although little is known about the role of
SS-IV in starch synthesis, recent research in Arabidopsis showed that it may function to control granule number [26]. Starch-branching enzyme isoforms SBEI and SBEII generate $\alpha(1,6)$ linkages that form the branched structure of amylopectin. SBEI plays an important but not exclusive role in the synthesis of B1-, B2-, and B3-chains. The SBEII- $a$ and SBEII- $b$ genes also perform a distinct function in the formation of A-chains [27-29]. Two groups of DBEs exist in plants: isoamylase type and pullulanase type (also known as limit dextrinases), which efficiently hydrolyze (debranch) $\alpha-(1-6)$-linkages in amylopectin and pullulan (a fungal polymer of malto-triose residues), respectively, and belong to the $\alpha$-amylase superfamily. One of the starch debranching enzymes, isoamylase (ISAI), is an essential player in the formation of crystalline amylopectin [18]. Pullulanase can supplement the function of isoamylase to some extent.

The genome sequence of Brachypodium distachyon L. was completed in 2010; analysis suggests Brachypodium is much more closely related to wheat and barley than to rice, sorghum, or maize [30,31]. In-depth studies of starch are necessary and significant because starch is a major storage carbohydrate in the seeds of cereal crops. Until now, considerable research has focused on various characteristics of Brachypodium, but the properties and development of starch granules remains poorly studied. We performed a comprehensive survey of the dynamic development of starch granules and regulation of starch synthesis in Brachypodium through comparative analysis with Triticum and Aegilops. We also studied the phosphorylation status of GBSSI, which controls amylase synthesis. Our results provide new insights into the molecular mechanisms of starch granule development and starch biosynthesis.

\section{Results \\ Development of grains and starch granules in Brachypodium}

The morphological features and dynamic changes in developing grains during 13 stages after flowering in $\mathrm{Bd} 21$, Chinese Spring (CS), and Ae peregrina are shown in Additional file 1. In all three genera, grain size and weight gradually increased from flowering to maturity, but some developmental differences were apparent. The grains were rapidly elongated from 2 to $8 \mathrm{DPA}$ in $\mathrm{Bd} 21$ and from 2 to 12 DPA in CS and Ae peregrina; at subsequent developmental stages, grain length increased slightly, while grain width and weight gradually increased until maturity (Additional file 1A). Bd21 grain weight increased slightly throughout development, but increased rapidly from 2 to $20 \mathrm{DPA}$ in CS and Ae peregrina. At $30 \mathrm{DPA}$, the grain weight reached the highest value (Additional file $1 \mathrm{~B}$ ).

The dynamic accumulation patterns of starch granules in the grain endosperm and pericarp during grain 
development were examined by light microcopy and SEM. In this study, plenty of starch appeared in the pericarp at the beginning of the seed formation. As shown in Additional file 2, there was a thick pericarp layer with abundance of starch at 4 DPA that persisted through 12 DPA. Colored starch grains were observed throughout the stages of grain development (Figure 1A). In Bd21, the starch granules appeared $~ 8$ DPA; their diameter remained less than $10 \mu \mathrm{m}$ throughout growth and were thus classified as B-granules (Figure 1B). The starch granules in CS grew rapidly from 6 to 8 DPA but remained less than $10 \mu \mathrm{m}$ in diameter; growth slowed from 8 to $12 \mathrm{DPA}$ and yielded granules of diameter greater than $10 \mu \mathrm{m}$; these were classified as A-granules.

The B-granule, whose diameter was less than $10 \mu \mathrm{m}$, appeared at 12 DPA. These 2 kinds of starch granules gradually increased during the subsequent period with the average diameter of A-granules stabilized at 20-30 $\mu \mathrm{m}$ and the diameter of B-granules at approximately 4-6 $\mu \mathrm{m}$. The average granule diameter reached $10 \mu \mathrm{m}$ by 10 or $12 \mathrm{DPA}$ in Ae peregrina; these were classified as A-granules (Figure 1C). SEM of the variation in starch shape during grain development confirmed these results (Figure 2).
In order to confirm that there are only A-granules in Ae. peregrina and $\mathrm{B}$-granules in $\mathrm{Bd} 21$, we purified all the granules from $\mathrm{Bd} 21$ and Ae. peregrina, and A-granules and B-granules from CS (Figure 3A). Statistical analysis showed that granule diameter in $\mathrm{Bd} 21$ ranged from 4-6 $\mu \mathrm{m}$, similar to the B-granules of CS (Figure 3B), whereas the diameter of starch granules in Ae peregrina ranged from 20-30 $\mu \mathrm{m}$, similar to the A-granules of CS (Figure 3C).

\section{Chromosomal localization, domain conservation, and phylogenetic analysis of starch synthesis-related genes in Brachypodium}

To identify the key genes regulating starch biosynthesis, the consensus amino acid sequences previously annotated in rice, wheat, and maize were used to perform a BLAST search against the whole Brachypodium genome database (http://www.brachypodium.org/). Twenty-four nonredundant enzymes related to starch synthesis were identified. Their distribution on the five Brachypodium chromosomes and their domain structures are shown in Additional files 3 and 4 . The starch synthesis-related enzymes were distributed among five chromosomal regions, seven of which (AGPII-b, SBEI, SBEIII, SSII- $a$, SSI, GBSSI, and AGPL IV)

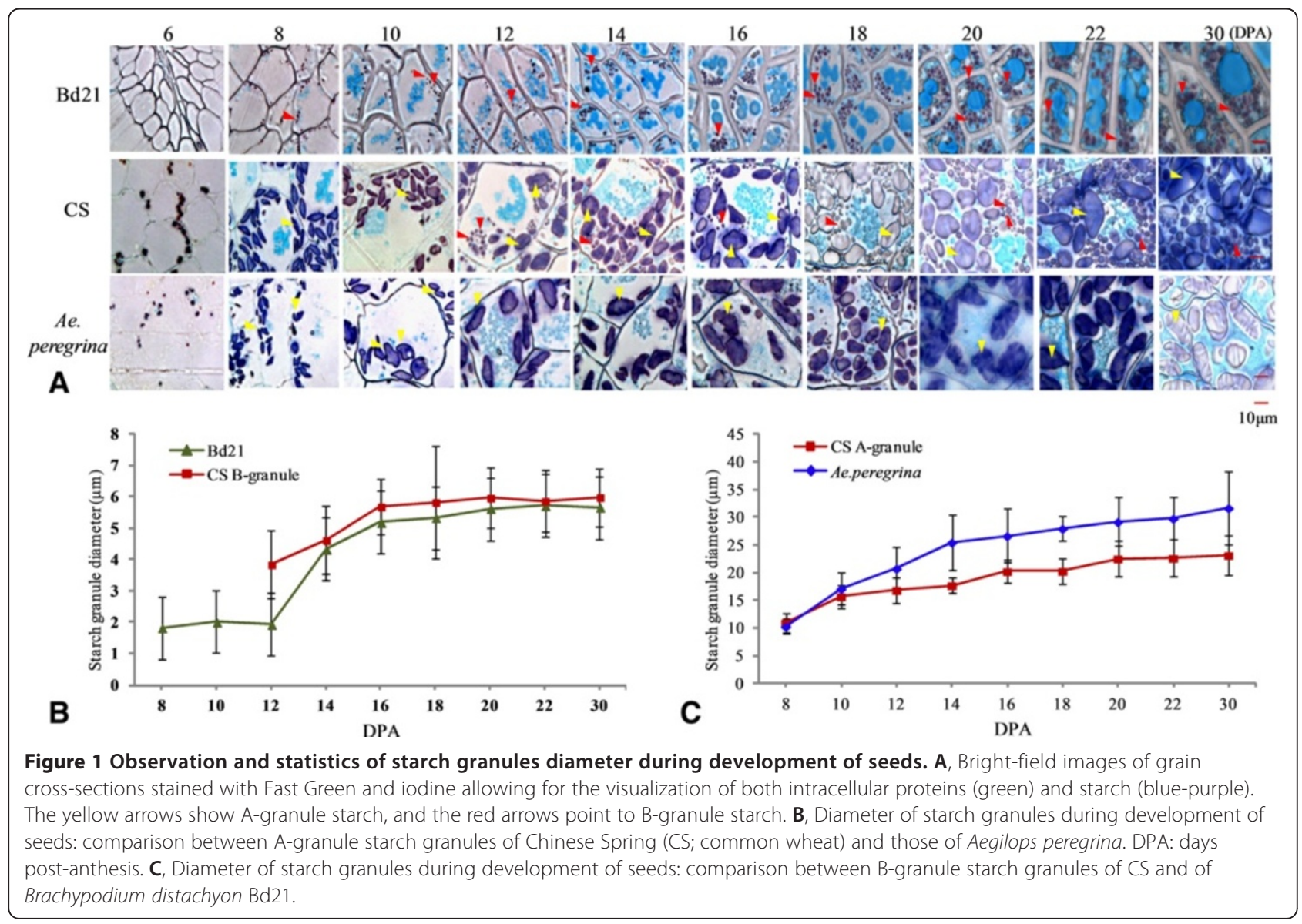




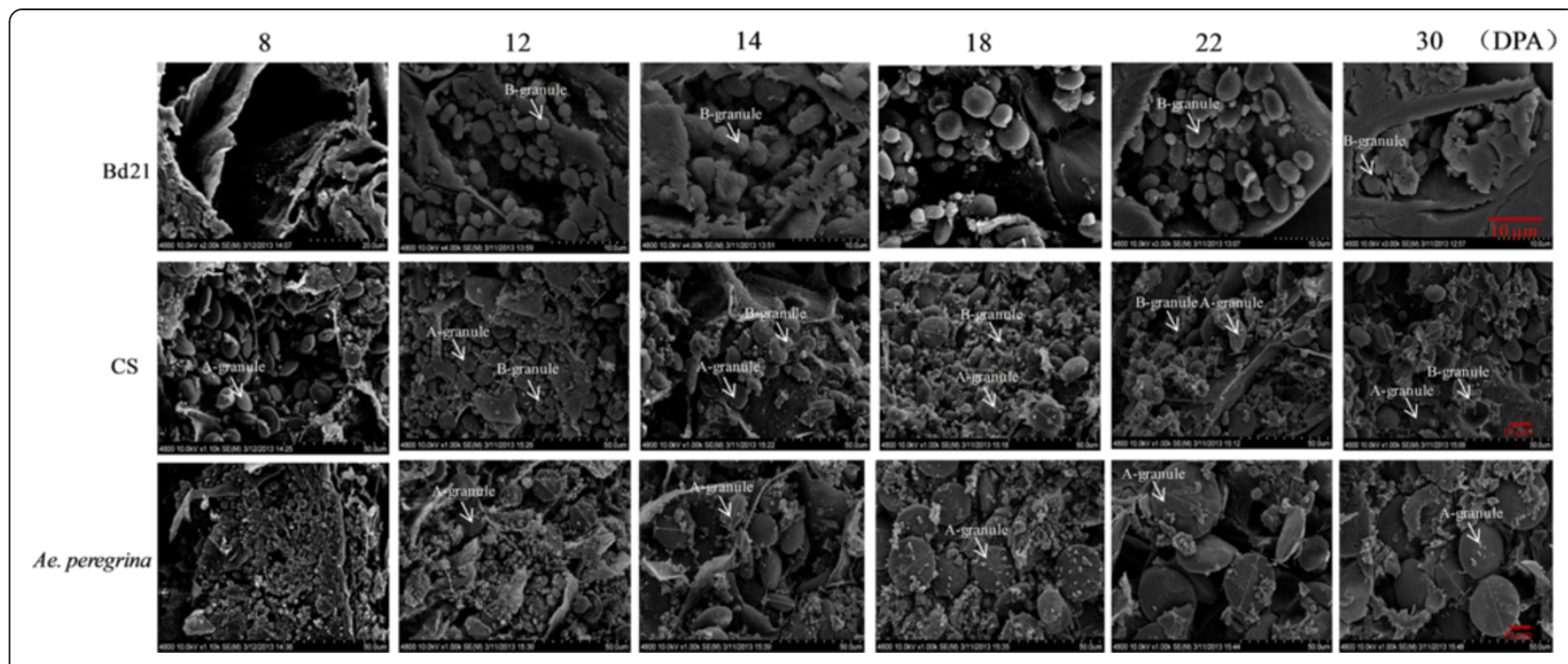

Figure 2 SEM images of grain cross-sections during grain development.
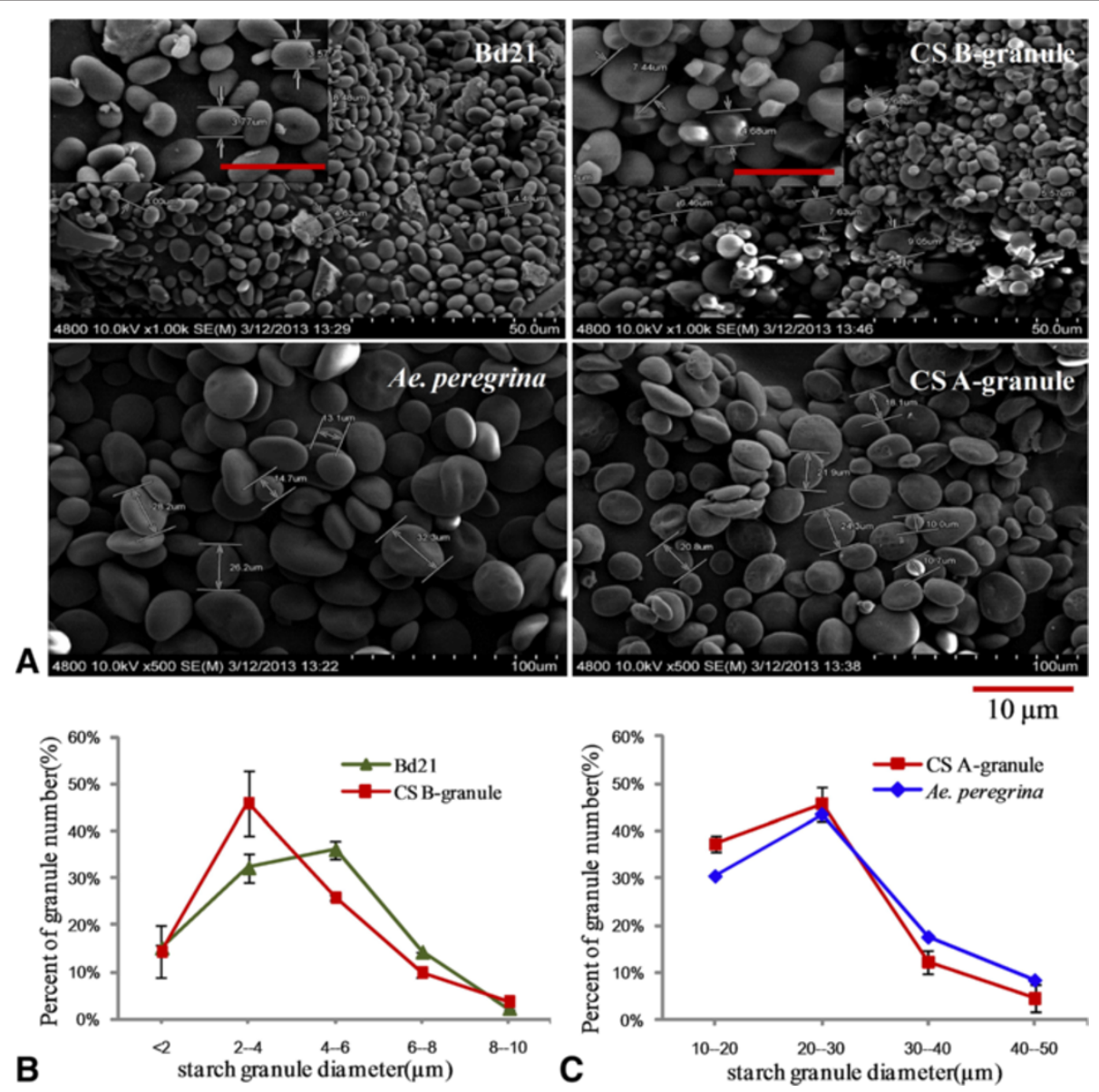

Figure 3 The distribution of diameters of starch granules in mature seeds. A, SEM of purified granules of Brachypodium distachyon Bd21 and Aegilops peregrina and of A-granule and B-granule starch granules of Chinese Spring (CS; common wheat). The scale bar is $10 \mu \mathrm{m}$. B, The distribution of diameters of starch granules among A-granule starch granules of CS and Ae. peregrina. C, The distribution of diameters of starch granules among B-granule starch granules of Bd21 and CS. 
were located on chromosome 1 from 0 to $74.8 \mathrm{Mb}$, four genes (AGPLI*, SSIV-b, ISAIII, and GBSSII) on chromosome 2 from 0 to $59.3 \mathrm{Mb}$, six genes (SSIII- $a$, SSII-c, ISAI, SBEII- $a$, AGPLIII, and SSII- $b$ ) on chromosome 3 from 0 to $59.8 \mathrm{Mb}$, three genes (SSVI-b, AGPSI, and ISA II ) on chromosome 4 from 0 to $48.6 \mathrm{Mb}$, and four genes (PUL, SBEII- $b$, AGPSII- $a$, and SSIII- $b$ ) on chromosome 5 from 0 to $28.1 \mathrm{Mb}$ (Additional file 3 ).

As shown in Additional file 4, starch synthases including GBSSI, GBSSII, SSI, SSII-a, SSII-b, SSII-c, SSIII-a, SSIII-b, and SSIV-b, are mainly composed of two structural domains: the starch synthase catalytic domain and the glycosyl transferase domain. SSIII-a and SSIII-b have a redundant carbohydrate-binding domain at the $\mathrm{N}$ terminus. SBEs and DBEs (except PUL) shared greater similarity, and all had the carbohydrate-binding module and an $\alpha$-amylase catalytic domain, but the SBEs contained one more $\alpha$ amylase $C$-terminal all- $\beta$ domain at the $C$ terminus. PUL is comprised of a carbohydrate-binding domain, $\alpha$-amylase catalytic domain, and a domain with an unknown function. ADP-glucose pyrophosphorylase small subunit (AGPS) had only one nucleotidyl transferase domain, whereas the ADP-glucose pyrophosphorylase large subunit (AGPS) contained a ribosomal protein L11 N-terminal domain and a ribosomal protein L11 RNA-binding domain (Additional file 4).

In order to understand the relationships among the 70 genes associated with starch synthesis in Brachypodium, rice, wheat, and maize, we constructed a phylogenetic tree (Additional file 5a). The genes were clearly separated into two groups: Group I included SSs and SBEs, whereas Group II consisted of DBEs and AGPases. Some key genes for starch synthesis were selected to construct different phylogenetic trees, including GBSSI, SSI, SBEI, SBEII-a, ISAI, PUL, and AGPL (Additional file 5b-g). Although the genes related to starch synthesis from Brachypodium, rice, wheat, and maize showed high similarity, most genes from Brachypodium were closer to those of wheat than rice and maize.

\section{Dynamic expression profiles of starch synthesis-related genes during grain development}

The dynamic expression profiles of 14 main starch synthesis-related genes during 12 grain developmental stages in Brachypodium $\mathrm{Bd} 21$ as well as common wheat (CS) and Ae. peregrina were analyzed by qRTPCR (Figure 4A-N) and melt curve analysis. Although the genes showed some similarities, their expression patterns were distinct during grain development in each of the studied genera. We observed six expression patterns: Type I (down-up), Type II (up-down), Type III (down-up-down), Type IV (up-down-up-down), Type V (down-up-down-up), and Type VI (up-down-up-downup-down) (Table 1).
Starch is composed of glucose polymers amylose and amylopectin. GBSSI, controlling amylose synthesis, displayed the down-up expression pattern (Type I) in Bd21 and exhibited higher early expression (4-8 DPA) and weaker expression at later stages (10-30 DPA). In contrast, GBSSI exhibited an up-down expression trend (Type II) and was mainly expressed at the intermediate stages of growth in wheat and Ae. peregrina (Figure 4A). Amylopectin synthesis is mainly controlled by SSs, SBEs, and SDEs. Two expression patterns (Type I and Type III) were exhibited in Bd21: the starch synthase (SSII- $a$ and SSIII- $a$ ) and starch branching enzyme (SBEI, SBEII- $a$ and SBEII- $b$ ) mainly exhibited a Type III expression pattern, whereas starch branching enzymes ISAI, ISAII, ISAIII, and PUL displayed a Type I expression pattern (Table 1). For example, SSII- $a$ and SSIII- $a$ showed a down-up-down expression trend (Type III) in $\mathrm{Bd} 21$, and was strongly expressed at 4 DPA and 18-25 DPA, and then moderately expressed during grain filling (8-16 DPA), but minimally expressed at 30 DPA (Figure 4C and 4F). ISA I and PUL exhibited a down-up pattern (Type I) in Bd21: expression was very strong at 4 DPA, decreased rapidly at 10 DPA, stabilized at the later stages, and then increased at 30 DPA (Figure $4 \mathrm{~K}$ and $4 \mathrm{~N}$ ). However, Type II was the main expression pattern observed in wheat and in Ae. peregrina. For instance, ISA I and PUL showed an up-down expression trend and were mainly expressed at the intermediate stages in wheat and at intermediate late stages in $A e$. peregrina (Figure $4 \mathrm{~K}$ and $4 \mathrm{~N}$ ). SS-I displayed a Type I expression pattern in $\mathrm{Bd} 21$ : down-regulation from 4 to 12 DPA and up-regulation from 12 to 30 DPA. In contrast, it exhibited an up-down pattern from 4 to 30 DPA and was expressed at lower levels in wheat and Ae. peregrina (Figure 4B). SSII-b and SSII-c exhibited the Type $\mathrm{V}$ expression trend (up-down-up-down) in all three genera (Figure 4D and 4E).

\section{Western blot analysis and immunolocation of GBSSI}

GBSSI is a key enzyme in amylase synthesis, and therefore it affects the physicochemical properties of flour and its end-products. Starch granule-binding proteins were extracted and fractionated by SDS-PAGE and silver-stained (Figure 5A). The isolated GBSSI was confirmed using matrix-assisted laser desorption ionization time-of-flight mass spectrometry (MALDI-TOF/TOF MS) (Additional file 6). The monoclonal antibodies against GBSSI (i.e., against its peptide) demonstrated high specificity to GBSSI (Figure 5B). The results showed three kinds of GBSSI in CS, corresponding to A, D, and B types [32] (Figure 5B). One and two protein bands were observed in Ae. peregrina and $\mathrm{Bd} 21$, respectively.

Immunogold labeling was used to determine the subcellular localization and the amount of GBSSI in 


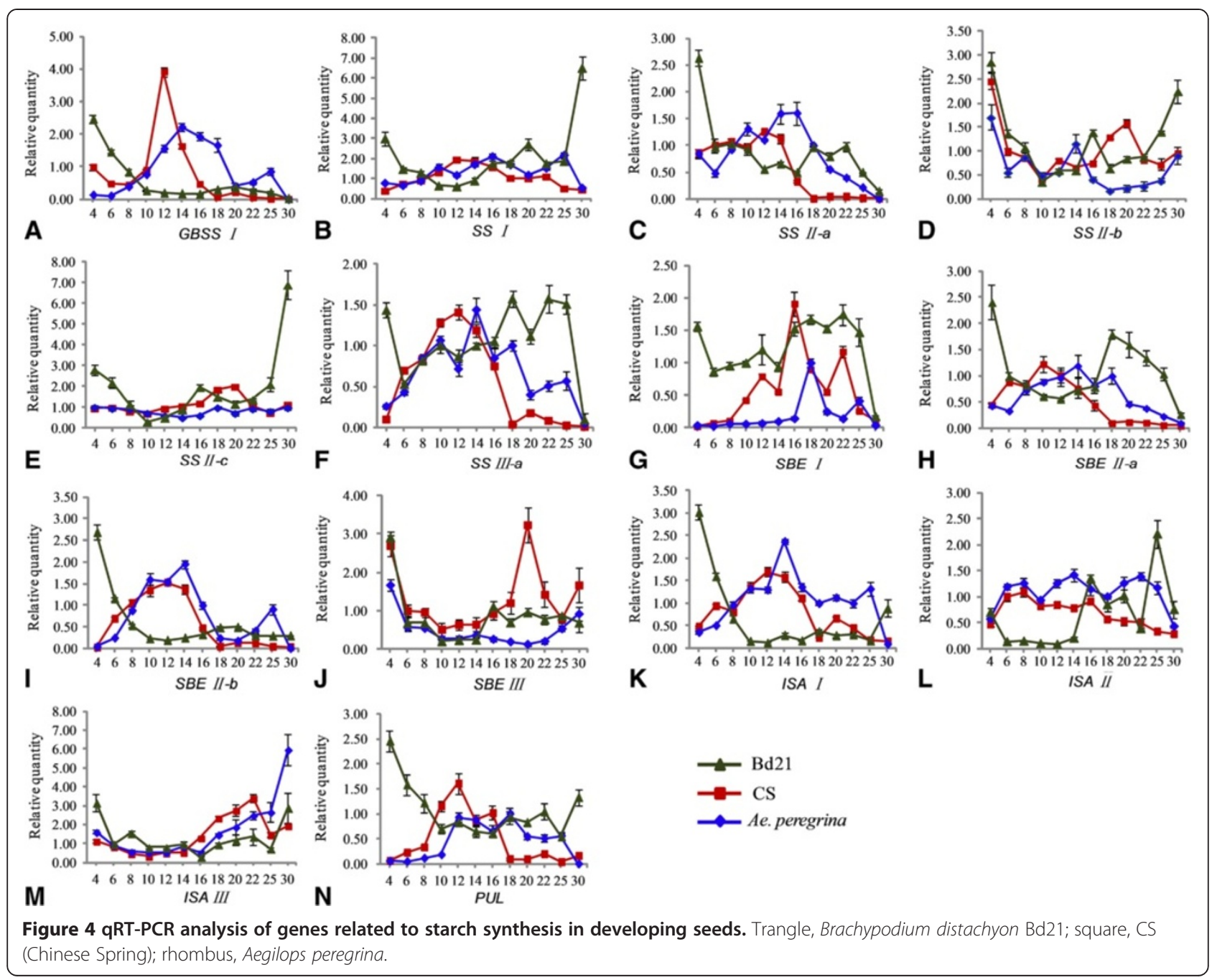

$\mathrm{Bd} 21, \mathrm{CS}$, and Ae peregrina. Ultrathin sections of 12-day-old immature seeds were processed as described in Methods. As shown in Figure 6, GBSSI was detected mainly in the starch granules of immature seeds. The amount of GBSSI in the B-granules of CS was greater than in Bd21, but the amount of GBSSI was similar in the A-granules of CS and Ae. peregrina.
Phosphorylation of GBSSI in starch granules during grain development

In this study, we detected two phosphorylated peptides: one at threonine 183 and one at tyrosine 185 in GBSSI of CS and Ae. peregrina (Additional file 7). The threonine and tyrosine residues were all located in the starch synthase catalytic domain (Figure 7A). However, no phosphorylation

Table 1 Expression pattern of the 14 genes in Brachypodium distachyon Bd21, Chinese Spring (CS; common wheat), and Aegilops peregrina

\begin{tabular}{llll}
\hline Pattern & Bd21 & CS & Ae. peregrina \\
\hline Type I (Down-up) & GBSSI, SSI, SBEIII, ISAI, ISAII, ISAIII, PUL & ISAIII & ISAIII \\
Type II (Up-down) & & GBSSI, SSI, SSII-a, SSIII-a, SBEI, & GBSSI, SSI, SSII-a, SSIII-a, \\
& & SBEII-a, SBEII-b, ISAI, ISAII, PUL & SBEI, SBEII-a, ISAI, PUL \\
Type III (Down-up-down) & SSII-a, SSIII-a, SBEI, SBEII-a, SBEII-b & \\
Type IV (Up-down-up-down) & & SBEII-2b \\
Type V (Down-up-down-up) & SSII-b, SSII-c, SBEIII & SSII-b, SSII-c, SBEIII \\
Type VI (Up-down-up-down- up-down) & & & ISAII \\
\hline
\end{tabular}




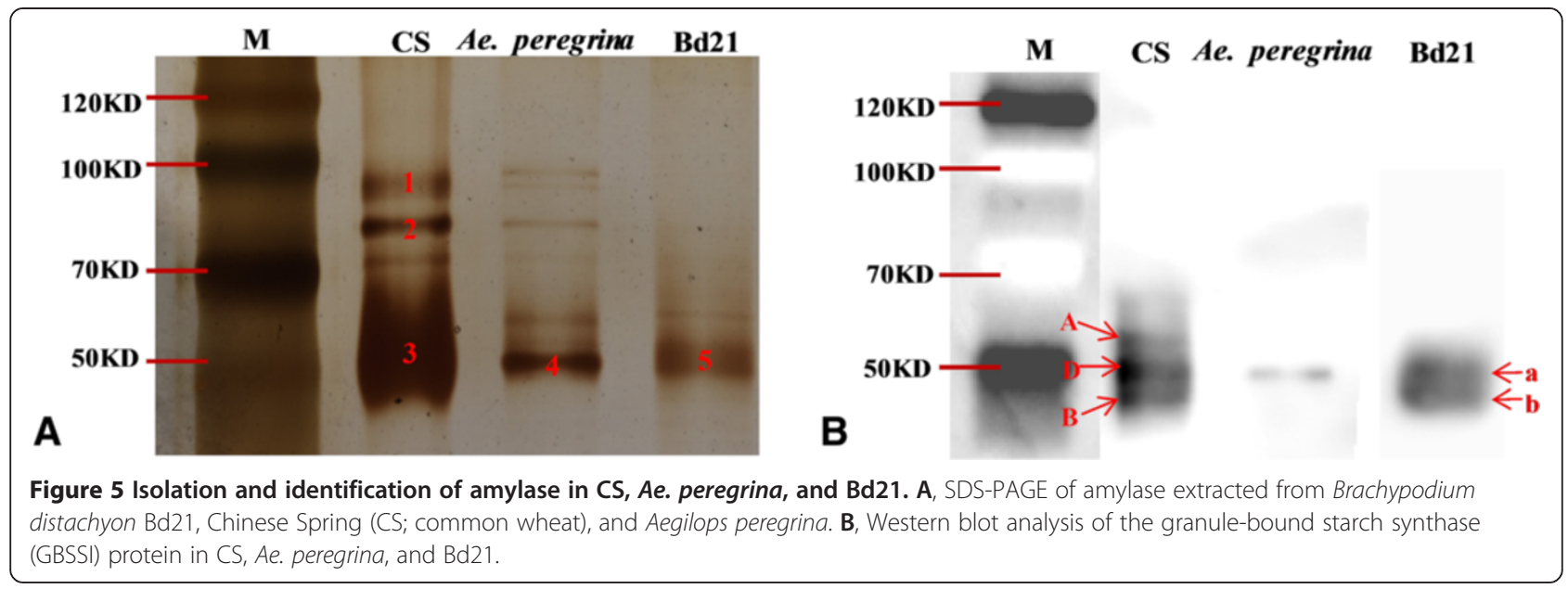

at this position was observed in $\mathrm{Bd} 21$. As shown in Figure 7A, the phosphorylated threonine in Triticum and Aegilops was replaced by valine in Brachypodium; this substitution may be responsible for the absence of phosphorylation in Bd21. The MS spectrum of a relevant phosphopeptide (Figure 7B) confirmed this result. The 3D structure of GBSSI (Figure 7C and 7D) was predicted using Phyre ${ }^{2}$ (http://swissmodel.expasy.org) and revealed the phosphorylated and unphosphorylated sites of CS and Bd21. The figure shows that in the 3D model, structurally relevant amino acids forming the starch synthase catalytic domain are well conserved. There are $12 \alpha$-helices and $11 \beta$-strands in the starch synthase catalytic domains of CS and Bd21, and the phosphorylated amino acid was always located between the third and fourth helix.

\section{Discussion}

\section{Brachypodium has only B-granules}

In mature wheat (Triticum aestivum L.), the endosperm contains three types of starch granules: A-granules $10-50 \mu \mathrm{m}$ in diameter and B-granules (including Cgranules) less than $10 \mu \mathrm{m}$ in diameter [8]. Previous studies confirmed that A-granules are formed at approximately 4-14 DPA and B-granules start to appear at approximately 10-16 DPA [6-8]. In this study, the starch granules in $\mathrm{Bd} 21$ appeared $~ 8 \mathrm{DPA}$, and their diameters were remained 4-6 $\mu \mathrm{m}$ until maturity. Thus, all starch granules
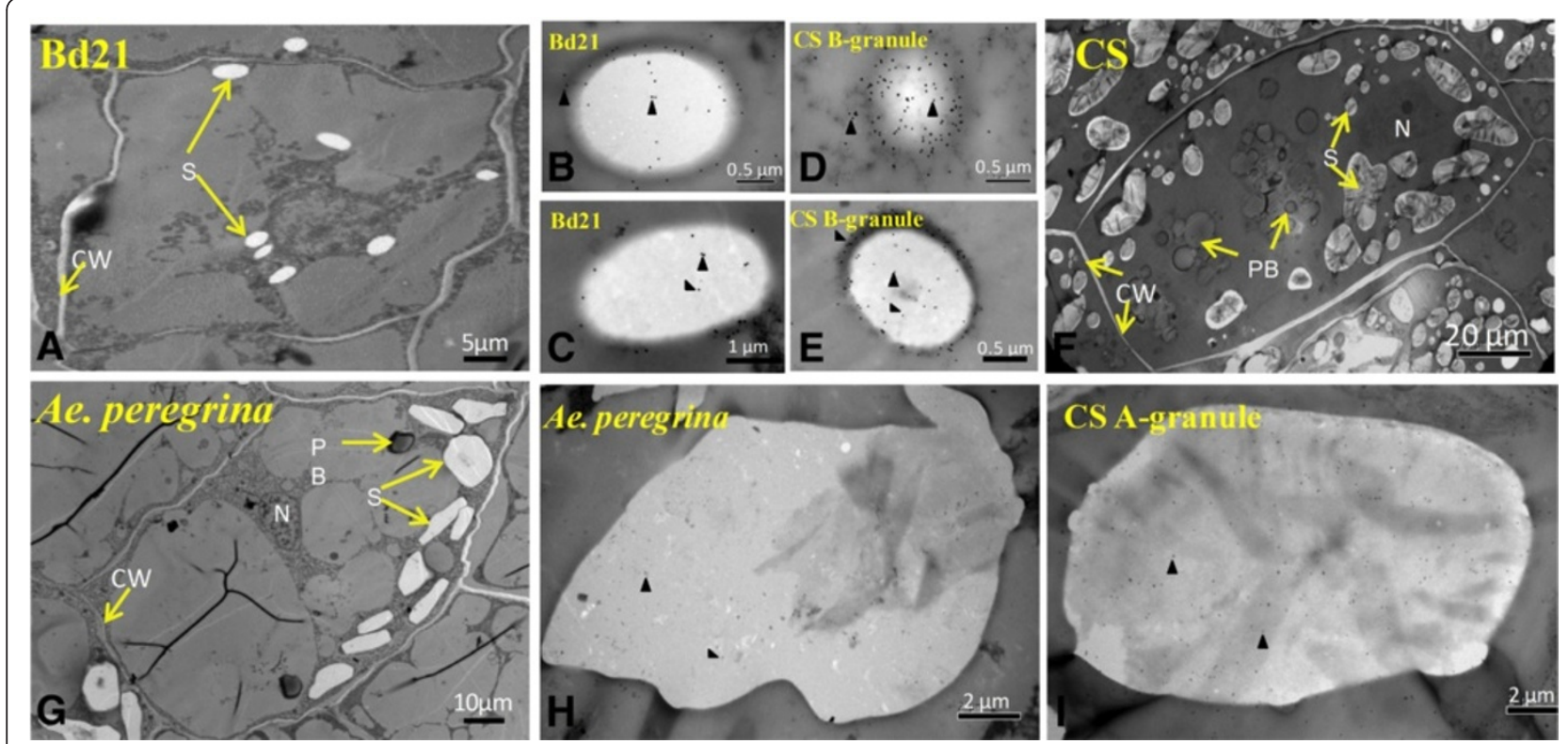

Figure 6 Immunolocalization of GBSSI in immature seeds (12 days post-anthesis [DPA]). A, F and G, Morphological observations. B-E, Immunocytochemical observation of B-granules. H-I, Immunocytochemical observation of A-granules. S, starch granules; PB, protein body; CW, cell wall; N, nucleus. Triangular arrowheads indicate gold particles. 


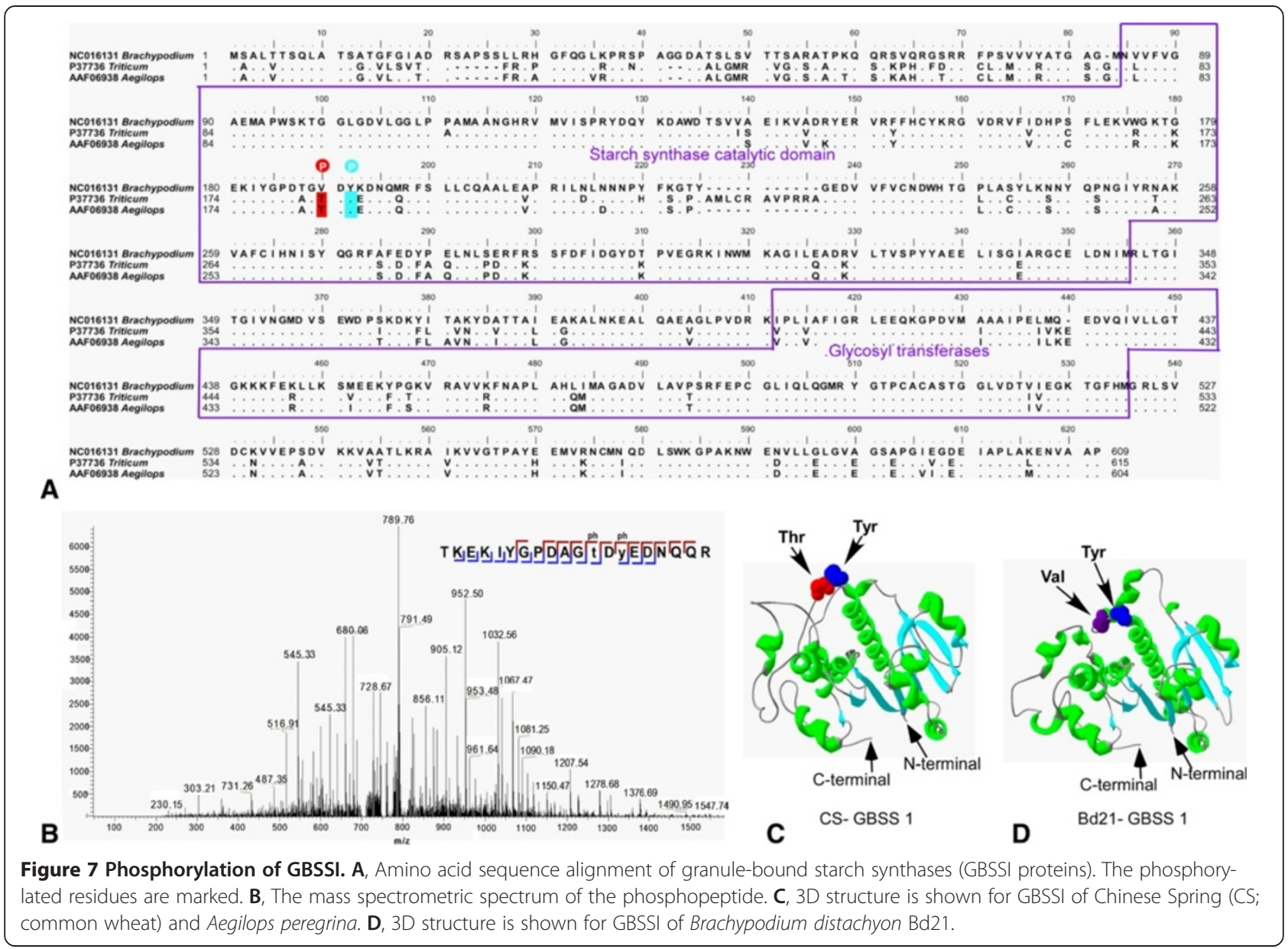

in $\mathrm{Bd} 21$ are B-granules. In contrast, Guillon et al. [33] showed that Bd21 starch granules start to appear at $\sim 17$ DPA. This is a bit longer than our observation, probably because of differences in growth conditions. B-granules in CS appeared at 12 DPA, and then, they grew slowly. Their diameter was mostly in the range of $4-6 \mu \mathrm{m}$. Agranules in CS showed rapid growth at early stages and reached $10 \mu \mathrm{m}$ at $10 \mathrm{DPA}$, and the diameter was mostly stable at $20-30 \mu \mathrm{m}$. Starch granules in Ae. peregrina appeared early and reached a diameter up to $10 \mu \mathrm{m}$ at 10 DPA; all starch granules in Ae. peregrina were A-granules, as reported previously [34]. Thus, CS had both A- and Bgranules whereas Ae. peregrina and $\mathrm{Bd} 21$ contained only A-granules or B-granules.

Brachypodium, Triticum, and Aegilops are closely related, although the sizes of their starch granules differ. The varied composition of A- and B-granules as well as diverse A:B granule ratios in Brachypodium, Triticum, and Aegilops suggest some genes specifically control the formation of A-granules and B-granules [35]. In wheat, a quantitative trait locus (QTL) associated with granule size was found on chromosome 4B [36], and the QTLs affecting the $\mathrm{A}: \mathrm{B}$ ratio of granules are located on chromosome 4DS [37]. In barley, a QTL affecting the shape of B-granules was identified on chromosome $4 \mathrm{H}$ [38]. A recent study showed that a major QTL controlling the content of B-granules is located approximately $40 \mathrm{cM}$ on the short arm of chromosome $4 \mathrm{~S}$ of Aegilops [34]. Those authors speculate that it is the tetraploidization event that leads to inactivation of the B-granule loci [34]. However, B-granules exist in all the diploid, tetraploid, and hexaploid lines of Brachypodium; thus, the polyploidization event may not be responsible for the lack of a B-granule site in Brachypodium. We speculate that the genes controlling A-granule loci may be silenced/ deleted during evolution. A recent study showed that Brachypodium has a highly conserved seed storage protein Gli-2 as well as a Glu-1 and a Glu-3 locus just like in Triticum and the related species, but almost no protein is detected because of abundant premature stop codons [39-41]. Moreover, previous analysis of Hardnesslike genes, the main determinants of the grain softness/ hardness trait in wheat, showed that Hardness-Brachy genes in Brachypodium could have been deleted independently during evolution [42]. We also theorize that the genes controlling A-granules may have been 
independently deleted/silenced when Brachypodium and Triticeae diverged nearly 35 million years ago $[43,44]$. Finally, from the standpoint of morphology, because Brachypodium cells are much smaller than those of other cereals, the larger A-granules are too hard to support. The major QTL controlling the content of A-and $\mathrm{B}$-granules has not been identified, and further research to map and identify the gene(s) responsible for A- or Bgranule initiation remains to be done.

\section{Expression of starch synthesis-related genes and starch biosynthesis}

The high expression level of starch synthesis-related genes at very early stages in Brachypodium attracted our attention. Other studies have shown that in the outer layers of cereal grains, starch accumulates transiently at the beginning of grain development, where it contributes to carbon storage during the earlier phases [45]. Nakamura et al. [46] reported that there is a thick pericarp layer with abundance of starch at 5 DPA, which persists until 20 DPA in wheat. The starch growth prevails in the early pericarp (0-4 DAF), then degenerates from 6 DAF [47]. In our study, abundant starch appeared in the pericarp at the beginning of seed formation (Additional file 2). As in barley, almost all genes showed low expression at 4 DPA in CS and Ae. peregrina, even though there were four genes, including SSIII- $a$, SBEI, SBEII- $b$, PUL, whose expression was nearly undetectable [48]. On the other hand, all of the 14 genes displayed high expression in $\mathrm{Bd} 21$ at 4 DPA (Figure 8). The high level of expression of genes during the early stages in Bd21 may be responsible for the production and accumulation of starch in the pericarp.

Nevertheless, these genes showed a relatively different expression pattern in the endosperm of these 3 genera. The amount of starch in the developing $\mathrm{Bd} 21$ seeds increased steadily between 8 and 20 DAF; in particular, the amount of starch showed an obvious increase at 16 and 18 DPA. At the same time, most of the genes exhibited high expression at approximately 16-18 DPA (Figure 8). The expected expression of starch synthesisrelated genes (especially SSI, SSII- $a$, SSIII- $a$, SBEI, SBEII- $a$, and $S B E I I-b)$ also appeared at 16 to $18 \mathrm{DPA}$, and may be responsible for the synthesis of $\mathrm{B}$-granules and increase of the endosperm. In this study, genes controlling synthesis of B-chains were expressed earlier than the genes related to A-chains. As shown in Figures 1 and 8, SSII- $a$ (controls synthesis of B1-chains), SSIII-a (controls synthesis of B2-chains) and SBEI (controls synthesis of B1/B2-chains or others) were expressed earlier than SS-I and SBEIIa and SBEIIb (control synthesis of A-chains). A-chains are linked to B-chains; therefore, B-chains should be synthesized early to provide support for A-chains. Although in CS, strong expression mostly appeared 12 DPA, which was responsible for the synthesis of B-granules, it is unexpected that SBEI was expressed later than SBEII- $a$ and $S B E I I-b$. The same phenomenon was also observed in Ae. peregrina: $S B E I$ was expressed later than SBEII-a and $S B E I I-b$ were. Since the sequence of SBEs in Brachypodium, wheat, rice and maize showed a high similarity and were classified into the same cluster, respectively (Additional file 5). We can hypothesize that SBEs in CS and Ae. peregrina have the functions that are opposite to those in Brachypodium, rice, and maize, which SBEI produces longer B-chains, whereas SBEII generates shorter A-chains [49,50]. In CS and Ae. peregrina, SBEII-a and SBEII-b may be responsible for the synthesis of longer B-chains, and SBEI may perform an important function in the synthesis of shorter A-chains. This hypothesis is supported by previous research in barley: Radchuk et al. [48] showed that SBEI expressed later than SBEIIs, and Regina et al. [29] suggested the reduction of SBEIIs led to a decrease of DP 10-18 chains in barley. Thus, the function of SBEs in wheat may be similar to that in barley, whereas the roles of SBEs in Brachypodium are the same as those in rice and maize. Although the sequences of SBEI and SBEIIs are different, the domains and $3 \mathrm{D}$ structure were similar, so it is possible that SBEs can have functions of mutual exchange in different species. DBEs are mutually complementary in the hydrolysis (debranching) of $\alpha-(1-6)$-linkages in amylopectin and pullulan during formation of new chains (Figure 8) [51]. The details regarding the function of DBEs are not known. In this study, ISA I, ISA II, and PUL displayed a down-up expression pattern in $\mathrm{Bd} 21$, which may be responsible for the hydrolysis of starch in the pericarp, whereas they showed an up-down pattern in CS and Ae. peregrina. It is known that the starch content of the endosperm is less than $10 \%$ of the whole Brachypodium grain, much less than that in wheat $(65-75 \%)$ [33]. On the other hand, there were only B-granules in Brachypodium, and the expression of starch synthesis-related genes was lower in the endosperm of Brachypodium compared to wheat and Ae. peregrina.

\section{Phosphorylation may play an important role in amylose synthesis}

Protein phosphorylation, as the most common posttranslational modification in vivo, regulates and controls biological processes such as transcription and translation, cellular and communication, proliferation and differentiation [52]. Other studies proved that the enzymes (proteins) binding starch granules, such as SSI, SSII-a, SBEI, SBEII-a, and SBEII-b, can be phosphorylated and can participate in protein-protein interactions [53,54]. Grimaud et al. [55] showed that GBSSI can be stained with a phosphoprotein-specific dye in maize; however, phosphorylation sites in GBSSI have not been identified. 


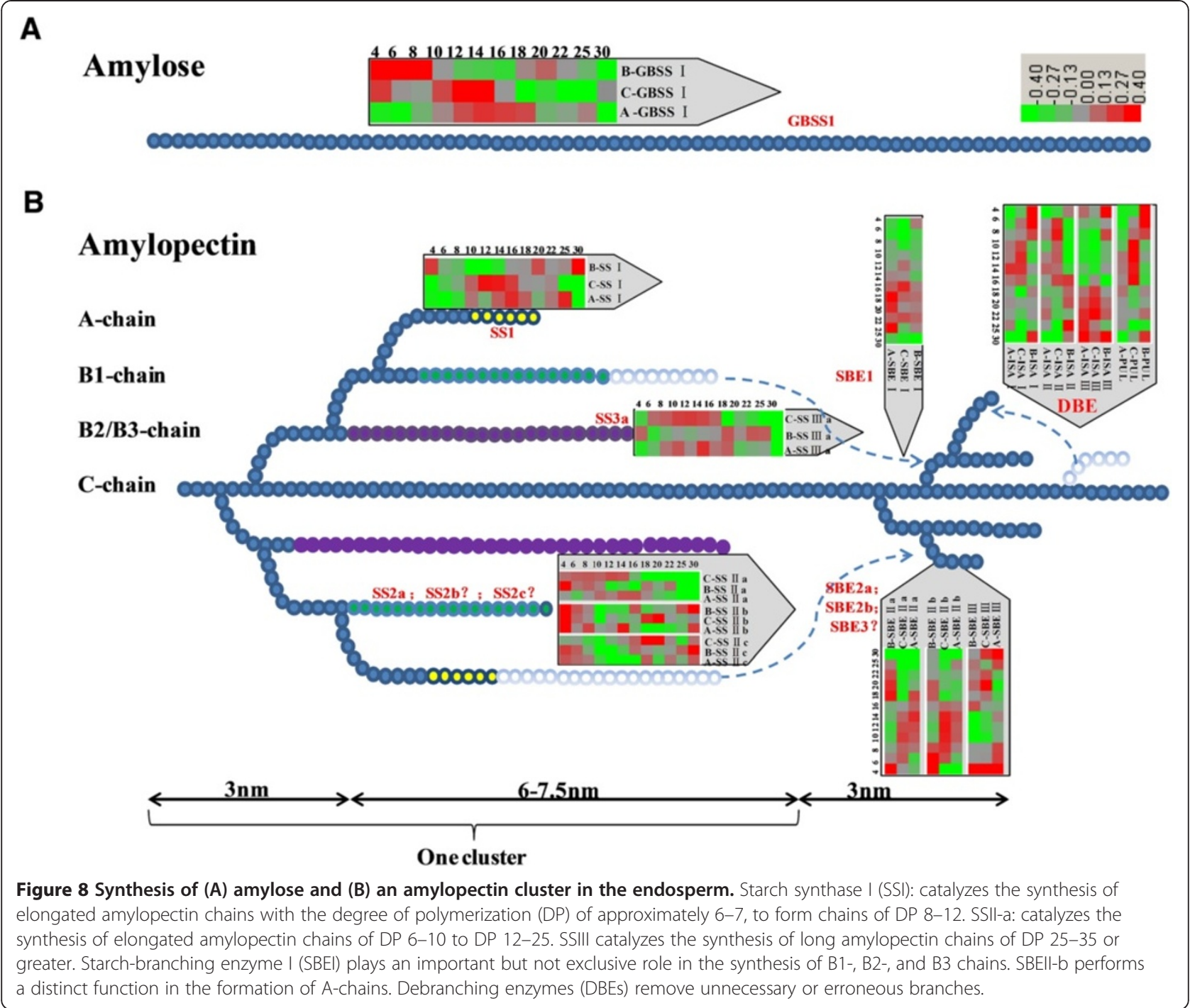

In this study, we identified two GBSSI phosphorylation sites in CS and Ae. peregrina, including threonine 183 and tyrosine 185, and both of which are located within the starch synthase catalytic domain. Although no phosphorylated peptides were found at these positions in $\mathrm{Bd} 21$, sequence alignment suggests the Thr183 in CS and Ae. peregrina is replaced by Val in $\mathrm{Bd} 21$; this substitution may be responsible for the lack of phosphorylation sites in Bd21. Few studies have described how phosphorylation sites influence amylase activity. Some have indicated that the starch synthase catalytic domain is responsible for glucan-substrate recognition and affinity; meanwhile, Tetlow et al. [53] showed that phosphorylation improves amylase activity and increases amylose synthesis; moreover, recent studies of the interaction of the farnesyl moiety with the hydrophobic patch on 14-3-3 showed that phosphorylation increases affinity between the interacting proteins $[56,57]$. Finally, amylose content is lower in B-granules ( 25\%) than in A-granules ( 30\%) [58]. Thus, we hypothesize that the phosphorylation sites in the starch synthase catalytic domain may play an important role in recognizing and attracting glucan substrates. We also propose the exciting possibility that phosphorylation increases the activity of GBSSI in A-granules and thereby improves amylose synthesis there. The influence of different phosphorylation sites for amylase activity requires further study.

\section{Conclusions}

We demonstrated the presence of only B-granules in $\mathrm{Bd} 21$, and they appear at $\sim 8$ DPA with a diameter of 4-6 $\mu \mathrm{m}$. The expression of key genes in the studied genera is consistent with the dynamic development of starch granules. The expression of key genes in starch biosynthesis of $\mathrm{Bd} 21$ mainly occurs at early and intermediate stages, for the synthesis of starch in the pericarp and 
for the increase of the number or size of starch granules, respectively. In contrast, the high expression of biosynthetic genes at intermediate stages in CS and Ae. peregrina is mostly responsible for production of new $\mathrm{B}$-granules and for the increase in the size of starch granules, respectively. The expression of the genes controlling synthesis of B1- or B2-chains occurs earlier compared to A-chains. GBSSI exists in B-granules of CS, in greater amounts compared to $\mathrm{Bd} 21$. There are two phosphorylation sites (Thr183 and Tyr185) in Triticum and Aegilops, whereas Thr183 was replaced by Val in Bd21. Phosphorylation of GBSSI may play a central role in amylose synthesis.

\section{Methods}

\section{Plant materials, planting, and sampling}

A diploid $B$. distachyon inbred line $\mathrm{Bd} 21$, the common wheat variety (Triticum aestivum L., $2 \mathrm{n}=6 \mathrm{x}=42$, AABBDD) Chinese Spring (CS), and Aegilops peregrina, accession \# AP200201 (2n $=4 \times=28$, SSUU) were used in this study. Ae. peregrina was kindly provided by the Department of Plant Breeding, Technical University of Munich, Germany. The grains were first stratified at $4{ }^{\circ} \mathrm{C}$ for $7 \mathrm{~d}$ on moist paper to promote synchronous germination, then transferred to soil and grown in a growth chamber at $21 / 18^{\circ} \mathrm{C}$ (day/night) and $65 \%$ relative humidity under a short-day (8/16 h light/dark) photoperiod with light intensity of $120 \mu \mathrm{mol} \mathrm{m}{ }^{-2} \cdot \mathrm{s}^{-1}$ for 4 weeks. The plants were then switched to long-day conditions with a $16 / 8 \mathrm{~h}$ light/dark photoperiod and the same light intensity. The plants were irrigated twice a week with a mineral nutrient solution. To harvest grains at defined developmental stages, individual flowers were tagged using colored tape at various stages post-anthesis. Grains were harvested at $4,6,8,10,12,14,16,18,20,22,25$, and 30 days post-anthesis (DPA).

\section{Light microscopy and scanning electron microscopy (SEM)}

A modification of Guillon et al. [33] was used for conventional chemical fixation. Grains were cut in transverse slices, approximately $3-4 \mathrm{~mm}$ thick, fixed in $3 \%(\mathrm{w} / \mathrm{v})$ glutaraldehyde and 4\% paraformaldehyde in 0.1 M PBS ( $\mathrm{pH} 7.4)$ overnight, after which samples were directly dehydrated in a series of ethanol solutions in water and then infiltrated and polymerized in medium-grade LR White resin. For light microscopy, sections approximately $1-\mu \mathrm{m}$ thick were prepared, and $10 \%(\mathrm{w} / \mathrm{v})$ fast green and $\mathrm{I}_{2}$ were used to stain the proteins and the starchy endosperm. In this study, three grains, nine sections, and $~ 600$ starch granules were used to quantify starch granule sizes at each stage.

Starch granules from different species and various grain developmental stages were dusted on the surface of a carbon-adhesive tab and sputter-coated with goldpalladium particles using Dentum Vacuum Desk II. SEM examination of starch granules was performed using a Hitachi Model S-4700 scanning electron microscope at $10.0 \mathrm{kV}$.

\section{Purification of starch granules}

Starch granules were separated and purified according to Branlard et al. [59] and Bancel et al. [60] with some modifications. The seeds were manually crushed and then soaked overnight in $1 \mathrm{~mL}$ of water at $4^{\circ} \mathrm{C}$. After centrifugation, $500 \mu \mathrm{L}$ of water was added to the pellet. The slurry was layered on $1 \mathrm{~mL}$ of $80 \%(\mathrm{w} / \mathrm{v}) \mathrm{CsCl}$ and centrifuged at $3500 \times g$ for $5 \mathrm{~min}$. The precipitate containing the starch granules was then washed 3 times with $1 \mathrm{~mL}$ of washing buffer (55 mM Tris- $\mathrm{HCl} \mathrm{pH} 6.8,2.3 \%$ [w/v] SDS, $1 \%$ [w/v] dithiothreitol [DTT], 10\% [v/v] glycerol) for $30 \mathrm{~min}$ at $20^{\circ} \mathrm{C}$. At the beginning of each washing step, the granules were disrupted using sonication by means of an ultrasonic processor (Vibracell, VC50, Bioblock Scientific, Illkirch, France) at the power of $20 \mathrm{~W}$ with a 20 -s pulse before continuous mixing. The granules were washed three times (10 min each time), and then washed three times (5 min each time) with cold water, once with cold acetone, and finally were air-dried. Each washing step was followed by centrifugation at $3500 \times g$ for $5 \mathrm{~min}$. All washing and centrifugation steps were carried out at room temperature to avoid precipitation of SDS. The purity of the starch fraction was monitored using SEM.

\section{Chromosomal locations, analysis of motifs, and construction of a phylogenetic tree}

The locations of the motifs in starch synthesis-related genes were confirmed using the database containing complete $B$. distachyon genome sequences [31]. Using the ClustalW software, we performed multiple alignments of the identified $B$. distachyon amino acid sequences of the genes related to starch synthesis with those from wheat and rice [61] using default options in the software. The phylogenetic tree was constructed using the bootstrap neighbor-joining (NJ) method with a Kimura 2-parameter model in the MEGA 4.0 software [62].

\section{RNA extraction, CDNA synthesis, and quantitative real-time PCR (qRT-PCR)}

Developing grains from the central part of the spikes in $\mathrm{Bd} 21, \mathrm{CS}$, and Ae. peregrina were harvested at 12 developmental stages of the grain $(4,6,8,10,12,14,16,18,20$, 22,25 , and 30 DPA). Total RNA of individual samples from different grain-developmental stages were extracted with TRIzol Reagent according to the manufacturer's instructions (Invitrogen), and the purification of mRNA was performed, as described by Li et al. [63]. With oligo(dT) and random primers, the mRNA was used to synthesize cDNA from approximately $100 \mathrm{ng}$ mRNA using the Superscript first-strand synthesis kit (Promega, Madison, 
WI, USA). The resulting cDNA was used for qRT-PCR analysis.

Transcriptional expression patterns of these genes were detected using qRT-PCR according to Paolacci et al. [64] with minor modifications, according to a 4-step protocol with a melting curve analysis: (1) initial incubation at $94^{\circ} \mathrm{C}$ for $3 \mathrm{~min}, 40$ cycles of (2) denaturation at $94^{\circ} \mathrm{C}$ for $15 \mathrm{~s}$, (3) hybridization at $58^{\circ} \mathrm{C}$ for $15 \mathrm{~s}$, and (4) extension at $72^{\circ} \mathrm{C}$ for $20 \mathrm{~s}$. The fluorescence signal was acquired at the end of the extension in every cycle. Specific primer pairs were designed for the genes using the Primer5.0 software by imposing the following stringent criteria: melting temperature of $58 \pm 2^{\circ} \mathrm{C}$, PCR amplicon length between 80 and $300 \mathrm{bp}$, primer length of $22 \pm 4$ bases, and $40-60 \%$ guanine-cytosine content. Primers were also designed within the $3^{\prime}$ region of each sequence to encompass all potential splice variants and to ensure equal RT efficiency. The complete set of primer pairs used for qRT-PCR analysis is shown in Additional files 8 and 9. The specific primers had a unique melting temperature peak. The efficiency of the primers was determined by means of standard curves using serial $\alpha$-gliadin gene dilutions; the efficiency ranged from $90 \%$ to $110 \%$ (Additional file 8 and 9), and R2 values (coefficient of determination) were calculated for standard curves higher than 0.993 for expression analysis of the genes and the candidate reference genes (Additional file 8 and 9). Triplicate PCRs were performed for each gene.

\section{Protein extraction and identification using tandem mass spectrometry (MS/MS)}

The seeds were manually crushed and soaked overnight in $1 \mathrm{~mL}$ of washing buffer $(70 \mathrm{mmol}$ Tris- $\mathrm{HCl} \mathrm{pH} 6.8$, $2 \%$ SDS, and $2 \% \beta$-mercaptoethanol) at $4{ }^{\circ} \mathrm{C}$. After centrifugation at $16000 \mathrm{rpm}$ for $1 \mathrm{~min}, 1 \mathrm{~mL}$ of washing buffer was added to the pellets, and the mixture was vibrated. After centrifugation (16000 rcf for $1 \mathrm{~min}$ ) and air drying, $1 \mathrm{~mL}$ of the extraction solution $(70 \mathrm{mmol}$ Tris- $\mathrm{HCl}$ $\mathrm{pH} 6.8$, 2\% SDS, $2 \% \beta$-mercaptoethanol, $20 \%$ glycerin, $0.005 \%$ bromophenol blue) was added, and then the pellets were boiled at $100^{\circ} \mathrm{C}$ for $4 \mathrm{~min}$. After centrifugation at $16000 \mathrm{rpm}$ for $1 \mathrm{~min}$, the supernatant was stored at $4^{\circ} \mathrm{C}$.

Protein bands were manually excised from the gels, and after trypsin digestion, these were analyzed on a 4800 Plus MALDI TOF/TOF Analyzer (Applied Biosystems, USA). All MS spectra were used for search in the NCBI database Viridiplantae (900091) and Triticum (16682) via the MASCOT software with GPS Explorer software version 2.0 (Applied Biosystems). The peptide tolerance was set as $100 \mathrm{ppm}$ and fragment mass tolerance was $0.4 \mathrm{Da}$. One missed cleavage was allowed, and carbamidomethyl (Cys) and oxidation (Met) were specified as variable modifications. MASCOT scores greater than $65(p<0.05)$ were accepted [65]. Protein identification by MALDI-TOF-MS is shown in Additional file 6.

Antibody development, Western blot, and immunolabeling The monoclonal antibody against GBSSI (peptide SEWDPAKDKFLA) was developed by Abmart (Shanghai, CHINA). The extracted proteins described above were separated by SDS-PAGE. After silver staining, the expected protein bands were collected and digested by trypsin, and then identified by MALDI-TOF/TOF-MS as described above. The identified GBSSI was further confirmed by western blotting according to Li et al. [63].

Cross-sections of 12-day-old immature grains were immediately cut into small pieces $\left(\sim 1 \mathrm{~mm}^{3}\right)$ and fixed with $4 \%$ glutaraldehyde in $0.1 \mathrm{M}$ PBS ( $\mathrm{pH} 7.4$ ) for $12 \mathrm{~h}$. Then, the samples were directly dehydrated in a series ethanol solutions, and permeated and polymerized in medium-grade LR White resin. Ultrathin (70 nm) sections were prepared on an ultramicrotome (Leica EM UC6) with a diamond knife and placed on Formvar-coated grids. Subsequently, the grids were rinsed for $2 \times 5 \mathrm{~min}$ in PBG (0.1 M PBS with $35 \mathrm{mM}$ glycine), and transferred to PBT (0.1 M PBS, 0.5\% BSA, and 0.02\% Tween 20) $2 \times 5 \mathrm{~min}$, then incubated overnight with an anti-GBSSI antibody diluted 1:1000. The sections were rinsed $6 \times 5$ min in PBT the next day, and the grids were incubated with a secondary antibody: a goat anti-mouse IgG antibody conjugated to colloid gold (Auroprobe-EM, GAR-G15; Janssen, Belgium) diluted $1: 20$ in the blocking solution (5\% skimmed milk, $0.1 \%$ Tween 20, and 0.2 M PBS) for $15 \mathrm{~min}$. The sections were washed $2 \times 2 \mathrm{~min}$ in PBT and $2 \times 2$ min in PBG followed by glass-distilled water, and then poststained with $2 \%$ uranyl acetate for $10 \mathrm{~min}$. Finally, the grids with sections were washed $6 \times 5$ min in PBG and were allowed to air dry before examination under the scanning transmission electron microscope. In the control experiment, the primary antibody was omitted to test for nonspecific secondary antibody binding [66,67].

\section{Identification of a phosphorylated peptide using liquid chromatography (LC) with MS/MS}

The identified GBSSI protein bands identified on the SDS-PAGE gel were cut into small pieces $\left(\sim 3-4 \mathrm{~mm}^{3}\right)$, then washed $2 \times 10 \mathrm{~min}$ in water. Then the minced gel was washed for $10 \mathrm{~min}$ in $200 \mu \mathrm{L}$ of $50 \mathrm{mM} \mathrm{NH} \mathrm{HCO}_{3}$ : $\mathrm{ACN}$ (1:1), and we repeated this step until all the color was gone. We then added $10 \mathrm{mM}$ DTT (10 $\mu \mathrm{L} 1 \mathrm{M}$ DTT) and $990 \mu \mathrm{L} 50 \mathrm{mM} \mathrm{NH}_{4} \mathrm{HCO}_{3}$ to the tube and kept the gels at $56^{\circ} \mathrm{C}$ for $1 \mathrm{~h}$. After cooling to room temperature, we removed the supernatant, added $50 \mu \mathrm{L}$ Iodoacetamide (IAM) $\left(22 \mu \mathrm{L} 1 \mathrm{M}\right.$ IAM, $\left.378 \mu \mathrm{L} 50 \mathrm{mM} \mathrm{NH}_{4} \mathrm{HCO}_{3}\right)$, and incubated the mixture in the dark for $45 \mathrm{~min}$. After that, we used $25 \mathrm{mM} \mathrm{NH}_{4} \mathrm{HCO}_{3}, 50 \% \mathrm{ACN}$, and $\mathrm{ACN}$ in this order to wash the strips, and vacuum-dried them for 
$5 \mathrm{~min}$. Finally, trypsin hydrolysis was conducted at $4^{\circ} \mathrm{C}$ for $60 \mathrm{~min}$ and at $37^{\circ} \mathrm{C}$ for $16-18 \mathrm{~h}$ in this order.

For MS analyses, peptides were resuspended in $0.1 \%$ formic acid (FA) and analyzed on an LTQ Orbitrap Elite mass spectrometer (Thermo Fisher Scientific) coupled online to an Easy-nLC 1000 (Thermo Fisher Scientific) in the data-dependent mode. The sample was trapped on a $150-\mu \mathrm{m} \times 0.5-\mathrm{mm}$ precolumn and eluted from an analytical $75-\mu \mathrm{m} \times 150-\mathrm{mm}$ column. Peptides were separated using a linear gradient formed by $2 \% \mathrm{ACN}$ (acetonitrile) in 0.1\% FA (mobile phase A) and 98\% ACN in $0.1 \%$ FA (mobile phase B), from $3 \%$ to $30 \%$ of mobile phase B in $90 \mathrm{~min}$. The mass spectrometer was operated with full scan acquisition in the Orbitrap at 24000 Da resolution $(350-1800 \mathrm{~m} / z)$. The mass spectrometer was set up to acquire collision-induced dissociation (CID) MS/MS scans after each MS1 scan of the 25 most abundant ions with MSA central losses of $\mathrm{m} / \mathrm{z}$ 98, 49, and 32.6. For CID, the normalized collision energy was set to 35 .

The MS data were analyzed with MaxQuant software, version 1.3.0.5, and were used to search the NCBI database. During the searching, the enzyme specificity was set to trypsin with the maximum number of missed cleavages of 2. Oxidized methionines, phosphorylation addition to serine, threonine, or tyrosine, and $\mathrm{N}$-terminal protein acetylation were included in the search as variable modifications. Carbamidomethylation of cysteines was included in the search as a fixed modification. The false discovery rate (FDR) for peptides, proteins, and site identification was set to $1 \%$.

\section{Additional files}

Additional file 1: Development of seeds. (A) Whole seeds at the 13 stages of seed development in Brachypodium distachyon Bd21, Chinese Spring (common wheat), and Aegilops peregrina. (B) Changes in fresh weight of developing seeds. Error bars represent SD of 3 replicates.

Additional file 2: Micrographs of peripheral cell layers at the early stages of grain development in Brachypodium distachyon Bd21, Chinese Spring (CS; common wheat), and Aegilops peregrina. Legend: DPA, days post-anthesis; en, endosperm; nu, nucellus tissue; pe, pericarp; ne, nucellar epidermis.

Additional file 3: Chromosomal locations of the key genes in starch biosynthesis annotated along the 5 chromosomes of Brachypodium distachyon Bd21. Chromosome numbers and sizes $(\mathrm{Mb})$ are indicated at the bottom of each bar.

Additional file 4: Analysis of motifs of key genes in Brachypodium distachyon $\mathrm{Bd} 21$.

Additional file 5: Phylogenetic analysis of key genes in starch biosynthesis among Brachypodium, wheat, rice and maize. a.

Phylogenetic tree was constructed based on the nucleotide sequences of 70 key genes in starch biosynthesis from Brachypodium, wheat, rice and maize. b-g. GBSSI, SSI, SBEI, SBEII-a, ISAI, PUL, and AGPL were selected to construct different phylogenetic trees.

Additional file 6: Protein identification by matrix-assisted laser desorption ionization time-of-flight mass spectrometry (MALDI-TOF MS).
Additional file 7: Phosphorylation identification of granule-bound starch synthase (GBSSI) in Chinese Spring (common wheat) and in Aegilops peregrina. Lowercase $t$ and $y$ represent the phosphorylation sites.

Additional file 8: Efficiency and R2 values (coefficient of determination) of primer pairs. Data were calculated from standard curves (5-fold dilution series from pooled cDNAs) in Brachypodium distachyon $\mathrm{Bd} 21$

Additional file 9: Efficiency and R2 values (coefficient of determination) of primer pairs, when calculated for standard curves (5-fold dilution series from pooled cDNAs) in Chinese Spring (common wheat) and Aegilops peregrina.

Competing interests

The authors declare that they have no competing interests.

\section{Authors' contributions}

GC, JZ and JZ carried out all experiments and data analysis. SS, MZ, CH and $\mathrm{PH}$ performed the preparation of CDNA, qRT-PCR and bioinformatics analyses $X \mathrm{~L}$ and $\mathrm{YY}$ conceived the study, planned experiments, and helped draft the manuscript. All authors read and approved the final manuscript.

\section{Acknowledgments}

This research was financially supported by grants from the National Natural Science Foundation of China (31271703, 31101145), International Science \& Technology Cooperation Program of China (2013DFG30530), Natural Science Foundation of Beijing City and the Key Developmental Project of Science and Technology, Beijing Municipal Commission of Education (6122002, KZ201410028031), and the National Key Project for Transgenic Crops in China (2011ZX08009-003-004).

Received: 19 March 2014 Accepted: 15 July 2014

Published: 6 August 2014

\section{References}

1. Hurkman WJ, McCue KF, Altenbach SB, Korn A, Tanaka CK, Kothari KM: Effect of temperature on expression of genes encoding enzymes for starch biosynthesis in developing wheat endosperm. Plant Sci 2003, 164:873-881.

2. Whistler RL, Daniel JR: Molecular structure of starch. In Starch: Chemistry and Technology, Ed 2. Edited by Whistler RL, Bemiller JN, Paschall EF. New York: Academic Press; 1984:153-182.

3. Peat S, Whelan WJ, Thomas GJ: Evidence of muitiple branching in waxy maize starch. J Chem Soc 1952, 886:4546-4548.

4. Hanashiro I, Abe J, Hizukuri S: A periodic distribution of the chain length of amylopectin as revealed by high-performance anion-exchange chromatography. Carbohydr Res 1996, 283:151-159.

5. Hughes CE, Briarty LG: Stereological analysis of contribution made to mature wheat endosperm starch by large and small granules. Starch-Stärke 1976, 28:336-337.

6. Langeveld SMJ, Wijk RV, Stuurman N, Kijne JW, Pater SD: B-granule granule containing protrusions and interconnections between amyloplasts in developing wheat endosperm revealed by transmission electron microscopy and GFP expression. J Exp Bot 2000, 51:1357-1361.

7. Bechtel DB, Wilson JD: Amyloplast formation and starch granule development in hard red winter wheat. Cereal Chem 2003, 80:175-183.

8. Wilson JD, Bechtel DB, Todd TC, Seib PA: Measurement of wheat starch granule size distribution using image analysis and laser diffraction technology. Cereal Chem 2006, 83:259-268.

9. Park SH, Wilson JD, Seabourn BW: Starch granule size distribution of hard red winter and hard red spring wheat: its effects on mixing and breadmaking quality. J Cereal Sci 2009, 49:98-105.

10. Soh HN, Sissons MJ, Turner MA: Effect of starch granule size distribution and elevated amylose content on durum dough rheology and spaghetti cooking quality. Cereal Chem 2006, 83:513-519.

11. Chiotelli E, Pilosio G, Le Meste M: Effect of sodium chloride on the gelatinization of starch: a multi-measurement study. Biopolymers 2002, 63:41-58.

12. Briarty $L G$, Hughes $C E$, Evers $A D$ : The developing endosperm of wheat: a stereological analysis. Ann Bot 1979, 44:641-658. 
13. Parker ML: The relationship between A-granule and B-granule starch granules in the developing endosperm of wheat. J Cereal Sci 1985 3:271-278.

14. Sahlström S, Brathen E, Lea P, Autio K: Influence of starch granule size distribution on bread characteristics. J Cereal Sci 1998, 28:157-164.

15. Lindeboom N, Chang PR, Tyler RT: Analytical, biochemical and physicochemical aspects of starch granule size, with emphasis on small granule starches: a review. Starch-Stärke 2004, 56:89-99.

16. Yonemoto PG, Calori-Domingues MA, Franco CML: Effect of granule size on the structural and physicochemical characteristics of wheat starch. Cienciae Tecnologia de Alimentos 2007, 27:761-771.

17. Vrinten P, Nakamura T: Wheat granule-bound starch synthase / and I/ are encoded by separate genes that are expressed in different tissues. Plant Physiol 2000, 122:255-263.

18. Morell M, Myers A: Towards the rational design of cereal starches. Curr Opin Plant Biol 2005, 8:204-210.

19. Ball S, Morell M: From bacterial glycogen to starch: Understanding the biogenesis of the plant starch granule. Annu rev Plant Biol 2003, 54:207-233.

20. Delvalle D, Dumez S, Wattebled F: Soluble starch synthase I: a major determinant for the synthesis of amylopectin in Arabidopsis thaliana leaves. Plant J 2005, 43:398-412.

21. Fujita N, Yoshida M, Asakura N, Ohdan T, Miyao A, Hirochika H, Nakamura Y: Function and characterization of starch synthase I using mutants in rice. Plant Physiol 2006, 140:1070-1084.

22. Zhang XL, Colleoni C, Ratushna V, Sirghle-Colleoni M, James MG, Myers AM: Molecular characterization demonstrates that the Zea mays gene sugary 2 codes for the starch synthase isoform SSIla. Plant Mol Biol 2004, 54:865-879.

23. Wang YJ, White P, Pollak L, Jane J: Characterization of starch structures of 17 maize endosperm mutant genotypes with Oh43 inbred line background. Cereal Chem 1993, 70:171-179.

24. Gao M, Wanat J, Stinard PS, James MG, Myers AM: Characterization of dull1, a maize gene coding for a novel starch synthase. The Plant Cell 1998, 10:399-412.

25. Jane J, Chen YY, Lee LF, McPherson AE, Wong KS, Radosavljevic M, Kasemsuwan T: Effects of amylopectin branch chain length and amylose content on the gelatizination and pasting properties of starch. Cereal Chem 1999, 76:629-637.

26. Roldan I, Wattebled F, Lucas MM, Delvallé D, Planchot V, Jiménez S, Pérez Ricardo, Ball S, D'Hulst C, Mérida Á: The phenotype of soluble starch synthase IV defective mutants of Arabidopsis thaliana suggests a novel function of elongation enzymes in the control of starch granule formation. Plant J 2007, 49:492-504.

27. Yamanouchi H, Nakamura $Y$ : Organ specificity of isoforms of starch branching enzyme (Q-enzyme) in rice. Plant Cell Physiol 1992, 33:985-991.

28. Nishi A, Nakamura Y, Tanaka N, Satoh H: Biochemical and genetic effects of amylose-extender mutation in rice endosperm. Plant Physiol 2001, 127:459-472.

29. Regina A, Hashemi BK, Ling S, Li Z, Rahman S, Morell M: Control of starch branching in barley defined through differential RNAi suppression of starch branching enzyme Ila and Ilb. J Exp Bot 2010, 61:1469-1482.

30. Draper J, Mur LAJ, Jenkins G, Ghosh-Biswas GC, Bablak P, Hasterok R, Routledge APM: Brachypodium distachyon: A new model system for functional genomics in grasses. Plant Physiol 2001, 127:1539-1555.

31. The International Brachypodium Initiative: Genome sequencing and analysis of the model grass Brachypodium distachyon. Nature 2010 463:763-768.

32. Debiton C, Bancel E, Chambon C, Rhazi L, Branlard G: Effect of the three waxy null alleles on enzymes associated to wheat starch granule $s$ using proteomic approach. J Cereal Sci 2010, 52:466-474

33. Guillon F, Larre C, Petipas F, Berger A, Moussawi J, Rogniaux H, Santoni A, Saulnier L, Jamme F, Miquel M, Lepiniec L, Dubreucq B: A comprehensive overview of grain development in Brachypodium distachyon variety Bd21. J Exp Bot 2011, 63:1-17.

34. Howard T, Rejab NA, Griffiths S, Leigh F, Michelle LW, Simmonds J, Uauy C, Trafford K: Identification of a major QTL controlling the content of B-granule starch granules in Aegilops. J Exp Bot 2011, 62:2217-2228.

35. Stoddard FL, Sarker R: Characterization of starch in Aegilops species. Cereal Chem 2000, 77:445-447.
36. Batey IL, Hayden MJ, Cai S, Sharp PJ, Cornish GB, Morell MK, Apples R: Genetic mapping of commercially significant starch characteristics in wheat crosses. Aust J Agric Res 2001, 52:1287-1296.

37. Igrejas G, Faucher B, Bertrand D, Guibert D, Leroy P, Branlard G: Genetic analysis of the size of endosperm starch granules in a mapped segregating wheat population. J Cereal Sci 2002, 35:103-107.

38. Borèm A, Mather DE, Rasmusson DC, Fulcher RG, Hayes PM: Mapping quantitative trait loci for starch granule traits in barley. J Cereal Sci 1999, 29:153-160.

39. Subburaj S, Chen GX, Han CX, Lv DW, Li XH, Zeller FJ, Hsam SLK, Yan YM: Molecular characterisation and evolution of HMW glutenin subunit genes in Brachypodium distachyon L. J App/ Genet 2013, doi:10.1007/ s13353-013-0187-4.

40. Wang SL, Wang K, Chen GX, Lv DW, Han XF, Yu ZT, Li XH, Ye XG, Hsam SLK, Ma WJ, Appels R, Yan YM: Molecular characterization of LMW-GS genes in Brachypodium distachyon L. reveals highly conserved Glu-3 loci in Triticum and related species. BMC Plant Biol 2012, 12:221.

41. Chen GX, Lv DW, Li WD, Subburaj S, Yu ZT, Wang YJ, Li XH, Wang K, Ye XG, Ma WJ, Yan YM: The a-gliadin genes from Brachypodium distachyon L. provide evidence for a significant gap in the current genome assembly. Funct Integr Genomics 2013. doi:10.1007/s10142-013-0353-0.

42. Charles M, Tang H, Belcram H, Paterson A, Gornicki P, Chalhoub B: Sixty Million Years in Evolution of Soft Grain Trait in Grasses: Emergence of the Softness Locus in the Common Ancestor of Pooideae and Ehrhartoideae, after their Divergence from Panicoideae. Mol Biol Evol 2009, 26:1651-1661

43. Bossolini E, Wicker T, Knobel PA, Keller B: Comparison of orthologous loci from small grass genomes Brachypodium and rice: implications for wheat genomics and grass genome annotation. Plant J 2007, 49:704-717.

44. Faris JD, Zhang Z, Fellers JP, Gill BS: Micro-colinearity between rice, Brachypodium, and Triticum monococcum at the wheat domestication locus Q. Funct Integr Genomics 2008, 8:149-164.

45. Sakri FAK, Shannon JC: Movement of 14 C-labeled sugars into kernels of wheat (Triticum aestivum L.). Plant Physiol 1975, 55:881-889.

46. Nakamura T, Vrinten P, Hayakawa K, Ikeda J: Characterization of a Granule-Bound Starch Synthase Isoform Found in the Pericarp of Wheat. Plant Physiol 1998, 118:451-459.

47. Sreenivasulu N, Radchuk V, Strickert M, Miersch O, Weschke W, Wobus U: Gene expression patterns reveal tissue-specific signaling networks controlling programmed cell death and ABA-regulated maturation in developing barley seeds. Plan t J 2006, 47:310-327.

48. Radchuk W, Borisjuk L, Sreenivasulu N, Merx K, Mock HP, Rolletschek H, Wobus U, Weschke W: Spatiotemporal Profiling of Starch Biosynthesis and Degradation in the Developing Barley Grain. Plant Physiol 2009, 150:190-204.

49. Takeda Y, Guan H-P, Preiss J: Branching of amylose by the branching isoenzymes of maize endosperm. Carbohydr Res 1993, 240:253-263.

50. Guan H, Li P, Radosevich Jl, Preiss J, Keeling P: Comparing the properties of Escherichia coli branching enzyme and maize branching enzyme. Arch Biochem Biophys 1997, 342:92-98.

51. Streb S, Delatte T, Umhang M, Eicke S, Schorderet M, Reinhardt D, Zeeman SC: Starch Granule Biosynthesis in Arabidopsis Is Abolished by Removal of All Debranching Enzymes but Restored by the Subsequent Removal of an Endoamylase. The Plant Cell 2008, 20:3448-3466.

52. Thingholm TE, Jensen ON, Larsen MR: Analytical strategies for phosphoproteomics. Proteomics 2009, 9:1451-1468.

53. Tetlow IJ, Wait R, Lu Z, Akkasaeng R, Bowsher CG, Esposito S, Hashemi KB, Morell MK, Emes MJ: Protein Phosphorylation in Amyloplasts Regulates Starch Branching Enzyme Activity and Protein-Protein Interactions. The Plant Cell 2004, 16:694-708

54. Tetlow IJ, Beisel KG, Cameron S, Makhmoudova A, Liu F, Bresolin NS, Wait R, Morell MK, Emes MJ: Analysis of Protein Complexes in Wheat Amyloplasts Reveals Functional Interactions among Starch Biosynthetic Enzymes. Plant Physiol 2008, 146:1878-1891.

55. Grimaud F, Rogniaux H, James MG, Myers AM, Planchot V: Proteome and phosphoproteome analysis of starch granule-associated proteins from normal maize and mutants affected in starch biosynthesis. J Exp Bot 2008, 59:3395-3406.

56. Riou P, Kjær S, Garg R, Purkiss A, George R, Cain RJ, Bineva G, Reymond N, McColl B, Thompson AJ, O'Reilly N, McDonald NQ, Parker PJ, Ridley AJ: 14-3-3 Proteins Interact with a Hybrid Prenyl-Phosphorylation Motif to Inhibit G Proteins. Cell 2013, 153:640-653. 
57. Commuri P, Keeling PL: Chain-length specificities of maize starch synthase I enzyme: studies of glucan affinity and catalytic properties. The Plant J 2001, 25:475-486.

58. Ao ZH, Jane JL: Characterization and modeling of the A- and B-granule starches of wheat, triticale, and barley. Carbohydr Polym 2007, 67:46-55.

59. Branlard G, Bancel E: Protein extraction from cereal seeds. Methods Mol Biol 2007, 355:15-25.

60. Bancel E, Rogniaux H, Debiton C, Chambon C, Branlard G: Extraction and Proteome Analysis of Starch Granule-Associated Proteins in Mature Wheat Kernel (Triticum aestivum L.). J Proteome Res 2010, 9:3299-3310.

61. Thompson JD, Higgins DG, Gibson TJ: Improving the sensitivity of progressive multiple sequence alignment through sequence weighting, positionspecific gap penalties and weight matrix choice. Nucleic Acids Res 1994, 22:4673-4680.

62. Tamura K, Dudley J, Nei M, Kumar S: MEGA4: molecular evolutionary genetics analysis (MEGA) software version 4.0. Mol Biol Evol 2007, 24:1596-1599.

63. Li XH, Ma WJ, Gao LY, Zhang YZ, Wang AL, Ji KM: A novel chimeric LMW-GS gene from the wild relatives of wheat Ae. kotschyi and Ae. juvenalis: evolution at the Glu-3 loci. Genetics 2008, 180:93-101.

64. Paolacci AR, Tanzarella OA, Porceddu E, Ciaffi M: Identification and validation of reference genes for quantitative RT-PCR normalization in wheat. BMC Mol Biol 2009, 10:11.

65. Ge P, Ma C, Wang S, Gao L, Li X, Guo G, Ma W, Yan Y: Comparative proteomic analysis of grain development in two spring wheat varieties under drought stress. Anal Bioanal Chem 2012, 402:1297-1313.

66. Danscher G: Localization of gold in biological tissue. A photochemical method for light and electron microscopy. Histochemistry 1981, 71:81-88

67. Steinbrecht RA, Ozaki M, Ziegelberger G: Immunocytochemical localization of pheromone-binding protein in moth antennae. Cell Tissue Res 1992, 270:287-302.

doi:10.1186/s12870-014-0198-2

Cite this article as: Chen et al:: Dynamic development of starch granules and the regulation of starch biosynthesis in Brachypodium distachyon: comparison with common wheat and Aegilops peregrina. BMC Plant Biology 2014 14:198.

\section{Submit your next manuscript to BioMed Central and take full advantage of:}

- Convenient online submission

- Thorough peer review

- No space constraints or color figure charges

- Immediate publication on acceptance

- Inclusion in PubMed, CAS, Scopus and Google Scholar

- Research which is freely available for redistribution 